\title{
An Approach to the Development and the Promotion of Secondary Tourism Destinations: A Case Study of BuengKan - A Potential Tourism Destination in Northeastern Thailand
}

\author{
JusanaTechakana \\ Department of Business Administration, King Mongkut's University of Technology North Bangkok, Thailand \\ E-mail:drchvr@gmail.com
}

\begin{abstract}
The Government of Thailand has announced a policy to develop and promote 55 provinces of Thailand to become secondary tourism destinations, BuengKan is a new-born province in the Northern part of Thailand, which is not a popular tourism region compared to the Northern and the Southern regions of the country. Nonetheless, BuengKan has a high potential to become a popular secondary tourism destination because it has a lot of tourism resources to develop various types of tourism with many modes of accessibility. In order to formulate a strategy to develop and promote BuengKan to become a popular secondary tourism destination, guidelines and recommendations from all stakeholders, including the public sector, the private sector, the community sector, and the academic sector need to be gathered. A qualitative research was conducted by employing in-depth interviews with public officers, local politicians, chamber of commerce members, private entrepreneurs in tourism industry, prominent figures of community members, and scholars in the fields of tourism, marketing, and marketing communications. Their answers from the in-depth interviews have been analyzed and organized to formulate development and promotion strategies to make BuengKan a popular secondary tourism destination of Thailand
\end{abstract}

Keywords

Secondary Destination, Development Strategy, Promotion Strategy, BuengKan Province

Article Received: 10 August 2020, Revised: 25 October 2020, Accepted: 18 November 2020

\section{Introduction}

Thailand has promoted 22 provinces as popular primary tourism destination for many years. In order to increase its revenues from tourism, the Government of Thailand has issued a policy to develop and promote the rest 55 provinces to become secondary tourism destination. On March 22nd,2011, BuengKan was proclaimed the 77 th province of Thailand. It is the latest province separated from Nongkai Province for the purpose of better governance and more efficient security management.[1]Now.BuengKan is a newborn province of Thailand with a high potential to become a popular secondary tourism destination. Tourism in BuengKan has not yet been developed to the utmost potential; there are no strategies to develop and to promote tourism of Bueng Kan. Nonetheless, when taking a tourism resource audit of BuengKan, one will see that BuengKan has many tourism resources, which makes it possible to develop various types of tourism in BuengKan. There must be an integrated task force to work together coherently with frictionless co-operation to develop and promote tourism of BuengKan. The development and the promotion of tourism in this new-born province must gather inputs from all stakeholders involved. In order to get guidelines and recommendation, a research must be conducted, so that the findings will be used to develop and promote tourism of BuengKan in order that it will become a popular secondary tourism destination..

\section{Research Objectives}

1. To get guidelines and recommendations from all stakeholders involved in the development and the promotion of tourism in BuengKan.

2. To formulate strategies to develop and to promote tourism of BuengKan, so that it will become a popular secondary tourism destination.

\section{Literature Review}

Tourism is important for economic development. Tourism consists of many businesses, and it can create various jobs in the city. It can create multiple effects that make citizens of the city prosperous and have better standards of living. Tourism and economic development reinforce each other. For tourism to be a major factor of overall long-run economic growth, the government must set priorities regarding where and how to use resources for national economic growth. More resources should be allocated to tourism and travel industries prior to other segments. Major economic benefits derived from tourism activities include foreign exchange earnings, employments, and income. [2] Once a city has become a tourism destination, a vast amount of revenue will be generated, tax money will increase, and souvenirs will have higher sales volume. It can be concluded hat tourism can make to development, including foreign currency, income and employment. [3]Many developing countries benefit from increasing expenditure on tourism. It is not generally the case that tourism displaces other viable economic activities; rather, tourism provides a source of foreign exchange earnings for countries with little, or nothing else, to trade internationally. 
The economically poor can benefit through employment and the development of micro enterprise opportunities. [4]

A new-born city has a chance to be made a popular secondary tourism destination. In the development of tourism in a destination, the first thing to do is to conduct tourism resource audit to create tourism portfolio of the destination. It has been stated that portfolio analysis is a powerful strategic marketing tool. [5]To be a popular destination, a new born city must go through a process of branding. Critical to the creation of a durable destination brand is the identification of the brand's values, the translation of tourism resources into a suitably emotionally appealing personality with appealing contents. [6] While this is difficult to achieve in destination marketing, it is not impossible.[7] It involves the stakeholders crucial to the delivery of the destination brand messages with largely webdriven strategy. In the promotion of destination, storytelling is tactical interpretation to make a destination popular; therefore, storytelling and dialogue are recommended methods of marketing promotion practice. [8]Once the city has become a popular tourism destination, more entrepreneurs will invest in various tourism businesses, more jobs will be created, more tourists will come to visit, and more retired people will move to live in. To make a new-born city a popular tourism destination, there must be a task force consisting of public officers, local politicians, private entrepreneurs, prominent community members, and academicians to form development and promotion strategies of tourism. The development must look into all elements of tourism, and the promotion must include both marketing mixes and integrated marketing communications. Infrastructure must be fully developed, and all facilities must be ready to accommodate a greater number of tourists who will visit the city, once it has become a popular tourism destination. Human resource is a very important marketing mix to attract tourists; they have to learn how to provide impressive experiences by employing progressive, experiential and collaborative approach to tourism pedagogy.[9] Destination marketing organizations have to implement innovative and appropriate approaches; and use adequate tools and techniques in order to improve marketing activities effectiveness and efficiency. To promote a destination, it is highly recommended that a strong focus on a strategic marketing approach should be adopted and implemented. [10]

A successful development of tourism should be communitybased tourism. Community-based tourism (CBT) has often been cited as an alternative to mass tourism and an approach for tourism to become more sustainable. If developed well, CBT can become a poverty alleviation mechanism and a way to access improvements in quality of life, providing empowerment and greater economic benefit to individuals in local communities.[11]Community-based tourism has emerged as responsible tourism, pro-poor tourism, sports tourism and moral impacts of tourism. Involvement of community members is an integral part of the task force. They must be heard; their inputs must be well considered. The most important element is human resource; thus, it is essential that people working in tourism businesses and community members be friendly and willing to be effective brand ambassadors of the city. Training and public campaigns are needed to educate human resources and community members to become good hosts that welcome tourists who come to town. It is believed that satisfied tourists will repeat coming to town, and will refer the city to other tourists. Community-based tourism is an important concept of rural tourism. Rural tourism has been regarded as a means of economic and social development in rural areas.[12] CBT with community resident involvement is considered as a result of a local initiative, and it demonstrates longer life expectancy, faster growth, and more positive impacts on the local economy.

[13] Community-based tourism has emerged as responsible tourism, pro-poor tourism, sports tourism and moral impacts of tourism. [14]

\section{Research Methods}

This research is a qualitative method conducted by indepth interviewing key informants in various fields relevant to the development and the promotion of tourism destination; they are public officers responsible for the development and the promotion of tourism in BuengKan, local politicians, private entrepreneurs in tourism businesses, members of the Chamber of Commerce of the city, prominent figures of community members, and academicians in the fields of tourism, marketing, and marketing communications. The topics of interview were: SWOT of BuengKan, approaches to the development and the promotion of tourism of BuengKan, how to make BuengKan a popular secondary tourism destination, the role of the Government, the role of private entrepreneurs, the role of community members, the development of infrastructure, strategic marketing mixes, marketing communication tools to promote BuengKan, successful factors, and how to overcome all the challenges.

\section{Results}

Qualitative research findings: BuengKan has a lot of tourism resources that can be developed into various types of tourism: (1) authentic culture for cultural tourism, (2) natural beauty for sightseeing tourism, (3) temples, Buddha images, and popular Buddhist sages for religious tourism, (4) wilderness and mountains for adventure tourism, (5) hills and rivers for sports tourism, (6) orchards and ranches for agro tourism, and (7) reserved parks and forests for ecotourism. In order to develop and promote tourism of BuengKan, the task force must perform the following functions : (1) conducting tourism resource audit, (2) preserving, restoring, revitalizing, and modifying tourism resources according to their conditions, (3) preserving natural beauty of the city to retain its fame as the gem of the Northeastern part of Thailand, (4) involving all stakeholders in the development and the promotion of tourism of BuengKan, (5) fully developing infrastructure of the city, (6) managing all modes of accessibility, (7) improving the quality of all types of accommodations, (8) upgrading quality of products and services to the world class standards, (9) adhering to the philosophy of sustainability and principles of community-based tourism, (10) formulating a marketing strategy to position BuengKan according to its particular features, 11) launching an integrated marketing communication according to principles of content marketing 
with various story telling approaches both offline and online, (12) launching a project to educate citizens of the city to be proud of being citizens of BuengKan with a brand ambassador mindset to be friendly and gregarious hosts to welcome visitors, (13) organizing festive events as major events that lure tourists to visit the city, and (14) making sure that BuengKan has particularities that will be used as unique selling proposition (USP) of BuengKan.

The challenges in the development and the promotion of tourism of BuengKan are: (1) upgrading hotels and restaurants to world-class standards, (2) convincing the Government to build an airport in BuengKan, (3) cultivating residents of BuengKan to take pride in being citizens of BuengKan, and (4) amending laws to allow tourists to visit beautiful forests of BuengKan, which are in preserved areas where visitors can only go to see beautiful sceneries, but cannot have any recreational activities. With the existing laws, the beautiful parks and forests of BuengKan cannot attract a large number of tourists, (5) designating selling points to differentiate BuengKan with tourism particularities, and (6) formulating an effective integrated marketing communication campaign according to the principles of content marketing.

In conclusion, things that BuengKan must do to become a popular secondary tourism destination are: (1) using content marketing for storytelling, (2) leveraging resource-based view principles to select and enhancing relevant tourism resources to develop particularities of various types of tourism, (3) organizing many major festive and sports events to lure people to flock into the city during the events, (4) coming up with unique selling proposition (USP) of the city for differentiation, (5) fully developing all elements of tourism, (6) looking into all marketing mixes of tourism promotion-going beyond 4 P's of marketing mixes, (7) improving and upgrading products and services to world class standards, (8) training and educating people working in tourism businesses to have service minds and effective interactive skills, (9) preparing community members to be effective brand ambassadors and friendly hosts,

formulating tourism development and promotion programs by leveraging tourism resources of the city according to the philosophy of sustainability and the principles of community-based tourism, and (11) regarding all development and promotion programs as an extension of the Government policy to promote secondary tourism destination. .

Problems that all stakeholders should be aware of and must try to mitigate are as follows:

1. There are conflicts between public officers who stick to public policies and private entrepreneurs who try to make maximum profits. The two might not go together well. They need to be well balanced, This problem needs to be resolved. Policies should not hinder business operation. At the same time, business operation should not violate the philosophy of sustainability and the principles of community-based tourism.

2. Infrastructure in BuengKan needs to be improved to provide convenience for tourists. This issue includes accessibility infrastructure and ancillary services for tourists while they are in the city. Local politicians should pressure the central Government to launch a mega project of infrastructure development. The move must be expedited immediately.

3. Products, hotels, restaurants, and other facilities in BuengKan are under acceptable standards. There are no factors to motivate entrepreneurs' investment. There should be Government's subsidies to encourage investment. At the same time, there should be training programs on quality management to improve quality of products and services in tourism businesses in BuengKan.

4. Service providers in BuengKan have not been trained to provide world-class services; therefore, all entrepreneurs in tourism businesses must pay attention to the development of human resources. The training campaign should be organized by the Government as a part of the scheme of developing and promoting secondary tourism destinations because this is an integral part of success.

5. There is not a conspicuous task force responsible for tourism development and promotion of BuengKan. This type of task force is needed to perform the duty of destination management organization (DMO) with two pivotal functions, namely (1) development and (2) promotion. A frictionless co-operation among the members of this type of task force is needed to be successful. The task force must consist of all relevant stakeholders, especially prominent figures of community members, so that the development will adhere to the principles of communitybased tourism, which will benefit residents of the city.

6. Some residents of BuengKan do not feel proud of being citizens of BuengKan; they still want to be citizens of Nongkhai-the province from which BuengKan was separated. They think that Nongkhai is famous for its mysterious Naga legends. They see people flock into Nongkhai in October to participate in the festival of mysterious Naga firework shooing above the Maekong River. There is a need to change this situation. There must be a campaign to make them know more about BuengKan, to make them feel proud of being citizens of BuengKan, and to make them ready to be brand ambassadors of Bueng Kan. Ceremonies developed on the premises of Naga mysteries must be created to go beyond the event of watching mysterious firework shooting over the Maekong River.

7. At present, tourists do not know much about BuengKan; an integrated marketing communication campaign is needed to disseminate stories of BuengKan. The campaign should aim at branding, image and reputation building, and showing particularities of BuengKan. This will differentiate BuengKan and make it a popular secondary tourism destination to fulfill the Government policy to develop and promote secondary tourism destinations of Thailand.

8. At present, there is not enough budget for tourism development and promotion, as there is no entity to move for fund raising in this matter. A campaign to raise fund for tourism development and promotion must happen promptly, and local politicians must be leaders in this movement to pressure the local Government to provide sufficient budgets for tourism development and promotion of tourism of BuengKan..

9. Laws must be amended to allowed tourists to enter beautiful forests in BuengKan. Not only can tourists visit the forests to study biodiversity, but they should also be able to have some recreational activities in the forests. At present, there are laws that inhibit them to do so. In order to attract 
more tourists to come to enjoy beautiful forests with trees, mountains, and waterfalls, the laws must be amended. The balance between preservation and joys of tourism must be well managed.

10. At present, tourists have no ideas what they should buy as souvenirs when they visit BuengKan, despite the fact that BuengKan has many local products for tourists to buy as souvenirs, including silk, local food products, preserved fruits, and decorative artifacts made of rubber. There should be stories to create values for all of these products. A content marketing strategy is needed to make these products valuable among tourists. As shopping is a "must" for tourists when they go to different places, it is important that local products be made famous among tourists, so that they feel like coming to the place of origin. That means the city will become an attractive tourism destination.

11. In developing tourism of BuengKan, community members should be able to have their rights in managing all tourism resources in the city. People responsible for the formulation of development and promotion strategies should listen to their inputs to make them feel the sense of ownership and that they are integral parts of the development and promotion.

12. To become successful in developing and promoting tourism in BuengKan, human capital is truly a pivotal part of the scheme. Professional human resource management is needed to prepare service providers in tourism businesses to create memorable impressive experiences for tourists who visit BuengKan, so that they will repeat their visits as well as refer BuengKan to others.

13. People who are involved in the development and promotion programs should thoroughly study the Government policies to develop and promote secondary tourism destination, so that all activities to develop and promote tourism of BuengKan will be an extension of the central Government project to leverage tourism as a measure to alleviate poverty and raise standards of living among residents of the 55 provinces that are named as secondary tourism destination.

14. Finally, it is important that the development adhere to the philosophy of sustainable tourism. The trio of sustainability tourism must be well regarded. Wealth distribution must be egalitarian and fair; local citizens must benefit from tourism development. Social and cultural ways of life must be preserved; social orders of the city must be maintained. Quality of environment must be well managed, and natural resources must be well preserved.

All the challenges mentioned above have to be well taken and overcome for tourism development and promotion in BuengKan to become successful. It is important that all activities in the scheme get consents from community members who should get benefits from the development and the promotion of tourism. With its tourism resources, BuengKan has a high potential to become a popular secondary destination of Thailand, and if the development and the promotion scheme is successful, it will result in the economic development of the city. Tourism will have multiple effects that benefit residents of various occupations. Wealth will be distributed among local residents, resulting in higher standards of living among residents of the city.

\section{Conclusion And Discussion}

The findings from the research indicate that BuengKan has a very good chance to become a popular secondary tourism destination of Thailand. It is known widely that tourism is a right and quick way to generate revenues for any destination; therefore, there must be a task force responsible for developing and promoting tourism of BuengKan. They must perform a tourism resource audit, and decide what they need to do with the existing resources. Some of the resources should be enhanced; others might have to be modified and supplemented. Some cultural things and natural beauties are to be preserved. More tourism resources can be newly created, such as different events - festivals, sports events, or religious ceremonies. BuengKan can offer many types of tourism due to a variety of tourism resources in the city, and this render opportunities to create many positions of tourism in BuengKan.

Architectures of temples, ways of life, and religious ceremonies are among unique selling points of cultural tourism of BuengKan.. The task force should try to create and organize various types of events that will lure tourists to flock into town during the events. Some of them might be sports events that bring in both participants and spectators. Others can be religious events for those who look for pilgrimage tourism. All events should be able to be replicated, so that they become annual events. There should be at least one annual festive event that is extravaganza to bring more people to town. All the events organized should be considered particularities to differentiate tourism of BuengKan. With unique selling propositions, BuengKan will become an attractive secondary tourism destination, and with effective marketing along with integrated marketing communications, the city will soon become a popular secondary tourism destination bringing in revenues for the city as well as the residents of the city

Aggressive marketing and integrated marketing communication strategies are required, and they have to be launched promptly. It is necessary to make tourists know the city. The contents to tell stories of the city must project particularities of the city, and give rationale for tourists to visit the city. Positioning the city with different types of tourism will make the city a macro tourism destination, and gain a large customer base. Among popular types of tourism that attract tourists are: (1) cultural tourism with architectures and ways of life, (2) sightseeing tourism with natural beauty, (3) sports tourism with many sports arenas, (4) recreational tourism with many activities, (5) adventure tourism with mountains and wilderness, and (6) religious tourism with temples and ceremonies. In developing tourism for BuengKan to become a popular secondary tourism destination of Thailand, the task force should look into the possibilities to develop various types of tourism to position the city among different target tourists.

The task force must try to identify all obstacles, and try to overcome it. In order to overcome all the obstacles, all stakeholders involved in the task force must co-operate in an integrated fashion without any friction and conflict. They have to be synergistic, coherent, and harmonious. Conflicts between public officers and private entrepreneurs must be removed. Community members must be heard; their consents must be received prior to any decision. To go along 
with the global trend, the development must try to attain the position of sustainable tourism.

A content marketing strategy is very important part of the promotion. People responsible for the promotional campaign must know what stories of BuengKan to be told, and they must be well told. Approaches to tell stories should be well selected and created to tell the stories of BuengKan efficiently and effectively. Both offline and online channels should be employed to reach different targets. In the past, only mass media channels were means to disseminate information about a city, and that cost a lot of money. At present, online channels are more effective and less costly; therefore budgets are no longer constraints of promotional communication campaigns. Nowadays, digital channels, especially social media are available, and they cost a lot less than mass media. This makes it possible to run an integrated marketing communication campaigns to promote tourism of a secondary tourism destinations with small budgets.. Not only do those who are responsible for the promotion communicate with target tourists, but residents of the city should participate in the process of brand curation. They should use their own social media accounts to tell stories of the city as well. Tourists who are impressed with their experiences in BuengKan will also be brand curators to promote BuengKan as an attractive secondary tourism destination. It is important that all people in tourism businesses create impressive experiences for all visitors, so that they will help tell stories of BuengKan to curate brand equity for BuengKan tourism.

To develop and promote a secondary tourism destination, there might be several challenges that people in the development and the promotion of tourism have to be aware of and try to overcome. They are: (1) residents lack brand ambassador mindsets, (2) the city is not ready to accommodate a large number of tourists, (3) restaurants, hotels, and many other tourism businesses are not up to world-class standards, (4) ancillary services are not available, (5) amenities to enhance tourists' experiences are not available, (6) entrepreneurs and employees working in tourism businesses are not ready to work with a large number of tourists, there must be educational workshops and training sessions to prepare them to be ready to work with an increasing number of tourists, (7) product and service quality must be improved up to world-class standards, and (8) the philosophy of sustainable tourism must be upheld.

\section{Recommendations}

In order to develop and promote tourism in a secondary tourism destination, the following measures must be implemented:

- $\quad$ set up a task force consisting of all relevant stakeholders to work together with integration and frictionless co-operation to come up with a master plan of tourism development and promotion,

- make sure that all stakeholders in the task force are working to create synergy of development and promotion by working coherently and harmoniously,

- $\quad$ adhere to the philosophy of sustainable tourism to go along with the global trend, the tourism in any destination must be community based, all decisions made should receive consents from community members who preserve their rights of resource management in the development,

- make sure that wealth distribution is egalitarian and fair among citizens of the city,

- make sure that social and cultural ways of life are well preserved and maintained,

- make sure that the development is environmental friendly; quality of environment is well maintained,

- identify particularities of the city to position the city with relevant and appropriate types of tourism and to come up with unique selling proposition for the city

- do not forget to organize various types of major events as annual events on several occasions to bring more tourists into town during the event periods; try to look into possibilities of event creation and organization,

- make sure that the residents of the city are well prepared to be effective brand ambassadors and good hosts; provoke them to help communicate stories of the city both off line and online,

- make sure that principles of destination marketing management are deployed to promote a city as a popular secondary tourism destination as a donot-miss tourism destination with attractive particularities,

- develop and create values for souvenir products to attract people to come to buy souvenirs at the place of origin by using branding marketing strategies to create brand equity,

- believe in the power of communication; launch an integrated marketing communication campaign, and continuously carry on the campaign aggressively for at least a few years to come,

- develop tourism in a secondary tourism destination by looking into all tourism elements of tourism and going beyond the traditional 5 A's used in many development schemes in the past, The researcher has proposed a set of 12 A's as follows: (1) Accessibility-easy to travel to, (2) Accommodations - nice and comfortable lodging facilities, (3) Attractions - many things to see and to learn, (4) Activities - many things to do for memorable impressive experiences, (5) Amenities - many things to enhance happiness and joys of experiences, (6) Ancillaries - availability of services while staying at the destination, (7) Availability - the city is included in organized tour packages, (8) Atmosphere-clean and beautiful surroundings, (9) Amiability-friendly and gregarious residents of the destination, (10) Authorities - public officers with development and promotion mindset, (11) Artifacts-improving quality and designs of souvenirs to attract tourists to come to buy at the place of origin, and (12) Alliances - teaming up with adjunct cities to be perceived as a macro destination with many things to do, to see, to play, to learn, and to buy

- deploy all marketing mixes beyond 4 P's to make sure that the marketing strategic campaign contains 
all relevant tactical elements to come up with a comprehensive promotion campaign.

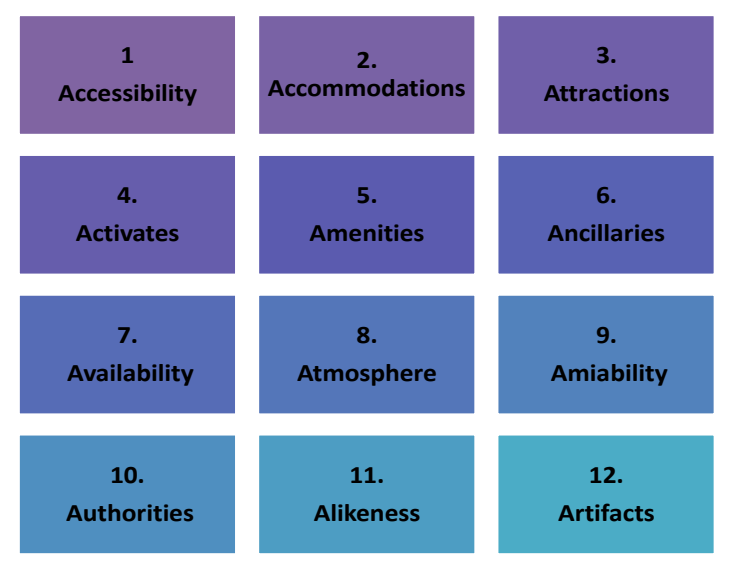

Fig.1: 12 A's Elements of Tourism Development

The researcher has proposed 18 P's of marketing mixes in promoting tourism in BuengKan; they are:

(1) Product--quality and relevance, (2) Price--reasonable and economical, (3) Place--easy to access and convenient connectivity (4) Promotion-- content marketing, (5) Particularity-strong differentiation, (6)Policy--communitybased , (7) People--personnel with service mind and interactive skills,

(8) Participation--effective involvement of all stakeholders,

(9) Program-- items included in tour packages, (10) Preservation-- sustainable tourism,

(11) Physical evidence-- beauty, cleanliness, signs, and safety, (12) Process--easy, convenience, fast, and consistent transaction, (13) Population: residents of the city are good hosts, (14) Partnership:--integrated services among all businesses in tourism industry clusters, (15) Provision:-sufficient budget for development and promotion, (16) Power: political power to launch projects of infrastructure development, (17) Ploy-many tactical activities and tools to keep a campaign dynamic, and (18) Positiondifferentiate a destination according to a repertoire of tourism resources of the destination, and manage relevant tourism resources according to the strategic concepts of resource-based view.
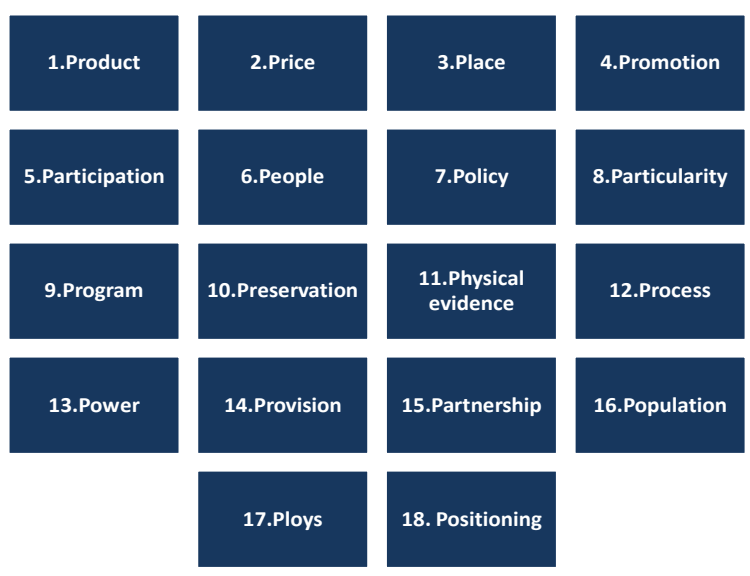

16.Population (20)

Fig.2 18. P's of Marketing Mixes to Promote Tourism for a City to Become a Popular Tourism Destination

\section{Final Note}

The coalition task force is a key success factor; all stakeholders must be involved. They should provide their inputs, ideas, and recommendations. Prominent figures of community members must participate; whenever they say something, they must be heard. Any decision made must have their consents. This is to make sure that the development gears at being a community-based tourism. The relevant stakeholders who should be parts of the task force are: the Governor of the city, public officers who are responsible for tourism development and promotion, public officers responsible for public relations of the city, members of the Chamber of Commerce, entrepreneurs of hotel business in the city, entrepreneurs of restaurant business in the city, community leaders, local politicians, and local academicians., Not anyone as mentioned above will be missing in the coalition task force, or else, the development and the promotion of tourism in a city will not be successful. All of the 55 provinces that will be made popular secondary tourism destinations must follow the guidelines of the Government policy that aim at using tourism to alleviate poverty. They must have development and promotion strategies to become popular secondary tourism destinations with a belief that they have to rely on tourism to generate revenues for their cities.. Tourism is vital to economic development of all secondary tourism destinations. Its multiple effects are tremendous, and people who run the city should never underestimate the economic power of tourism.

\section{References}

[1] BuengKan was proclaimed the 77 th"province of Thailand It is the latest province separated from Nongkoi Provinces for the purpose of better governance and more officering security management" On March 22,2011 (Wikikpedia. ,2011)

[2] H Kim, MChen,S Jang“Tourism expansion and economic development: The case of Taiwan Volume 27, Issue 5, October 2006, Pages 925-933

[3] M. Thea Sinclair"Tourism and economic development: A survey"Pages 1-51 | Accepted 01 Jan 1998, Published online: 23 Nov 2007

[4] H Goodwin "Tourism local economic development and poverty reduction" Applied Research in Economic DevelopmentVol, 5 issue3. December 2008 
[5] B Mckercher "The Destination-Market Matrix:"A Tourism Market Portfolio Analysis Model Pages 23-40 | Published online: 02 Nov 2010

[6] M Zapata ,C. Hall,P Lindo \&M VanderschaegheCan community-based tourism contribute to development and poverty alleviation? Lessons from Nicaragua"Pages 725-749 | Received 15 Oct 2010, Accepted 06 Jan 2011, Published online: 21 Mar 2011

[7] Nigel J. Morgan A Pritchard, R Piggott "Destination branding and the role of the stakeholders: The case of New Zealand "First Published July 1, 2003

[8] Ilja SimonsPower and empowerment in communitybased tourism: Opening Pandora's box?'Tourism Review 70(1):72-84,I: $\quad$ 10.1108/TR-06-20140035,April 2015

[9] T Jamal, J Taillon, D Dredge "Sustainable tourism pedagogy and academiccommunity collaboration: A progressive service-learning approach" April 2011

[10] M Soteriades "Tourism destination marketing: approaches improving effectiveness and efficiency" Journal of Hospitality and Tourism Technology,2012

[11]R Dodds,A Ali \&K Galaski“"Mobilizing knowledge: determining key elements for success and pitfalls in developing community-based tourism" Pages 15471568 Received 29 Jul 2015, Accepted 30 Jan 2016, Published online: 01 Mar 2016

[12] A Farmaki "An exploration of tourist motivation in rural settings: The case of roodos.Cyprus"Volumes 2-3AprilJuly Page 72-78,2012

[13] María José Zapata , C. Michael Hall , Patricia Lindo \& Mieke Vanderschaeghe "Can community-based tourism contribute to development and poverty alleviation? Lessons from Nicaragua" Current Issues in Tourism, Volume 14, 2011 - Issue 8Pages 725-749 | Received 15 Oct 2010, Accepted 06 Jan 2011, Published online: 21 Mar 2011
[14] O.Mtapuri, A. Giampiccoli C. Spershott "Community-based tourism research in academic journals: A numerical analysis" Received:

21 February 2015; Revision Accepted: 30 April 2015 